\title{
Synthesis, Magnetic, Spectral and Antibacterial Properties of Some Metal(II) Complexes of Mixed Drugs, Aspirin and Vitamin $B_{2}$
}

\author{
Aderoju A. Osowole*, Abiodun E. Odutemu \\ Inorganic Chemistry unit, Department of Chemistry, University of Ibadan, Nigeria
}

*Corresponding author: Aderoju A. Osowole, Inorganic Chemistry unit, Department of Chemistry, University of Ibadan, Nigeria, Tel: +2348097327529; E-mail: aderoju30@gmail.com

\begin{abstract}
Some metal(II) complexes of the mixed drugs-Aspirin and Vitamin $\mathrm{B}_{2}$ (Riboflavin) were synthesized and characterized by melting point, conductance, percentage metal measurements, as well as infrared and electronic spectroscopies. The electronic spectra, percentage metal analysis and conductance measurements corroborated octahedral geometry for all the metal complexes. Infrared data confirmed that metal complexes had $\mathrm{O}_{4}$ chromophores, that is, coordination was via the carbonyl oxygen atoms of the carboxylic acid and acetyl groups of the Aspirin; and hydroxy oxygens in Riboflavin. Furthermore, the room temperature magnetic data suggested that both the $\mathrm{Fe}$ (II) and the $\mathrm{Ni}$ (II) complexes exhibited spin-crossover, that is, low spin $\leftrightarrow$ high spin octahedral equilibrium, while the $\mathrm{Mn}$ (II) and $\mathrm{Cu}(\mathrm{II})$ complexes exhibited antiferromagnetism respectively. The drugs, Aspirin and Vitamin $\mathrm{B}_{2}$, and their metal(II) complexes were generally inactive against E.coli, Enterobacteria sp, Klebsiella sp, Bacillus sp, Staphylococcus aureus, Pseudomonas sp and Staphylococcus epidermidis, with the exception of Co(II), Ni(II) and $\mathrm{Cu}$ (II) complexes which showed some activities against Bacillus sp., Klebsiella sp. and Staphylococcus spp. with inhibitory zones in the range of $6.0-12.0 \mathrm{~mm}$ respectively.
\end{abstract}

Received Date: August 28, 2016

Accepted Date: Sept 12, 2016

Published Date: Sept 17, 2016

Citation: Osowole, A.A., Odutemu, A.E. Synthesis, Magnetic, Spectral and Antibacterial Properties of Some Metal(II) Complexes of Mixed Drugs, Aspirin and Vitamin $B_{2}$. (2016) Lett Health Biol Sci 1(2): 30- 33.

DOI: $10.15436 / 2475-6245.16 .009$

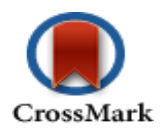

\section{Introduction}

Metal complexes are now the focus of drug designs due to the success of metallo drugs like Auranofin, Flamazine and Cis-platin ${ }^{[1]}$. This has expanded the data base on chemo therapeutic agents which are less toxic, with improved anticancer, antioxidant and antimicrobial activities. Thus, metal complexes could serve as lead compounds for the replacement of existing ones in the combat against toxicity and resistance ${ }^{[2]}$. Aspirin is an analgesic with anti-inflammatory and antipyretic actions ${ }^{[3,4]}$. On the other hand, riboflavin is a water-soluble vitamin that is used in the treatment of neonatal jaundice, migraine and together with UV light is effective for inactivation of pathogens in body fluids. Its deficiency results in sore throat, odema and anemia ${ }^{[5,6]}$. Literature is available on metal complexes of individual analgesics and vitamins including Aspirin and Riboflavin ${ }^{[7-10]}$. However, no information is available yet on the metal(II) complexes of the mixed drugs-Aspirin and Riboflavin ${ }^{[1-16]}$. Since metallo drugs contain a metal and $\operatorname{drug}(\mathrm{s})$ as active ingredients, we thought of using the metals, $\mathrm{Mn}, \mathrm{Fe}, \mathrm{Co}, \mathrm{Ni}, \mathrm{Cu} \& \mathrm{Zn}$, and Riboflavin (vitamin $\mathrm{B}_{2}$ ) being essential in humans, to act as mineral and vitamin supplements. The combination of the various metals, Aspirin and Riboflavin are also expected to improve antibacterial activities ${ }^{[17,18]}$. Our group, has over a decade focused on the search for novel metallo-analgesic and metallo-vitamin complexes as lead compounds in drug research for the management of pain and vitamin deficiency ${ }^{[13-16]}$. Thus, our aim was to synthesize the metal(II) complexes of the mixed drugs-Aspirin and Riboflavin $\{\mathrm{M}=\mathrm{Mn}, \mathrm{Fe}, \mathrm{Co}, \mathrm{Ni}, \mathrm{Cu} \& \mathrm{Zn}\}$ and investigate their magnetic properties for cooperative phenomena (spin crossover, ferro- and anti-ferromagnetisms). In addition their antibacterial properties against some pathogenic bacteria were also verified for their suitability as broad-spectrum antibacterial agents. 


\section{Materials and Methods}

$\left[\mathrm{Fe}(\mathrm{HL})\left(\mathrm{HL}^{2}\right) \mathrm{SO}_{4}\right] \cdot \mathrm{H}_{2} \mathrm{O}$ was prepared by the addition of $1.08 \mathrm{~g}\left(3.89 \times 10^{-3} \mathrm{~mol}\right)$ of $\mathrm{FeSO}_{4} .7 \mathrm{H}_{2} \mathrm{O}$ into a stirring homogeneous solution of $0.70 \mathrm{~g}\left(3.89 \times 10^{-3} \mathrm{~mol}\right.$ of Aspirin, HL) and $1.46 \mathrm{~g}\left(3.89 \times 10^{-3} \mathrm{~mol}\right.$ of Riboflavin, $\left.\mathrm{HL}^{2}\right)$ in $40 \mathrm{~mL}$ of hot methanol. The resulting coloured solution was then refluxed for six hours, after which the product formed on cooling to room temperature. The product was isolated by filtration, washed with methanol and dried over anhydrous $\mathrm{CaCl}_{2}$. Similar procedures were used for the preparation and isolation of the $\mathrm{Mn}(\mathrm{II}), \mathrm{Co}(\mathrm{II})$, $\mathrm{Ni}(\mathrm{II}), \mathrm{Cu}(\mathrm{II})$, and $\mathrm{Zn}(\mathrm{II})$ complexes from their acetate, chloride and sulphate salts respectively. A typical equation is shown below;

$\mathrm{HL}+\mathrm{HL}^{2}+\mathrm{FeSO}_{4} \cdot 7 \mathrm{H}_{2} \mathrm{O} \rightarrow\left[\mathrm{Fe}(\mathrm{HL})\left(\mathrm{HL}^{2}\right) \mathrm{SO}_{4}\right] \cdot \mathrm{H}_{2} \mathrm{O}+6 \mathrm{H}_{2} \mathrm{O}$

\section{Physical measurements}

IR (as $\mathrm{KBr}$ disc) and electronic (solid reflectance) spectra were recorded using a Perkin-Elmer FT-IR spectrum BX and a Perkin-Elmer $\lambda 25$ spectrometer respectively. The melting points of the ligands and the complexes were determined using a Gallenkamp melting point apparatus, while percentage metal was determined by complexometric titration using EDTA. An electrochemical analyzer consort C933 was used to determine molar conductance measurements of $1 \mathrm{mM}$ solutions in dimethyl sulphoxide. Single temperature magnetic moment susceptibility measurements were carried out using a Sherwood susceptibility balance MSB Mark 1 at a temperature of $30^{\circ} \mathrm{C}$.

\section{Antibacterial studies}

Laboratory strains of E. coli, S. epidermidis, S. aureus, Enterobacteria sp., Klebsiella sp., Bacillus sp., and Pseudomo- nas $s p$. were used for the screening. The antimicrobial experiments were carried out at the Department of Microbiology, University of Ibadan, Ibadan, Nigeria.

\section{Preparation of agar plates/samples}

Antibacterial susceptibility tests were performed using the agar diffusion technique. $10 \mathrm{~cm}^{3}$ of Muller Hinton's agar was poured into each of the Petri dish to set; afterwards their surfaces were uniformly inoculated with $0.3 \mathrm{~cm}^{3}$ of $18 \mathrm{~h}$ old test bacteria cultures. This was followed by the addition of $1 \mathrm{mM}$ solution of each compound in $3 \mathrm{~cm}^{3}$ of dimethyl sulphoxide to $6 \mathrm{~mm}$ wells bored into the agar. The plates were then left on the bench for 30 minutes to allow diffusion of the compounds into the agar, after which they were incubated at $37^{\circ} \mathrm{C}$ for 24 hours. The inhibitory zones diameters in $\mathrm{mm}$ were taken as an indicator of antimicrobial activities.

\section{Results and Discussion}

\section{Analytical data}

The metal complexes all showed expected coloration due to $\mathrm{d}-\mathrm{d}$ and $\mathrm{M} \rightarrow \mathrm{L}$ CT transitions. The melting points of the ligands and their metal(II) complexes were distinctively different, that is, Aspirin decomposed at $136^{\circ} \mathrm{C}$, Vitamin $\mathrm{B}_{2}$ melted at $280^{\circ} \mathrm{C}$, and the metal complexes mostly decomposed above or below the melting point and decomposition temperature of their respective parent drugs due to coordination. The percentage metal and experimental values, of the complexes were well within the range of theoretical values (Table 1) and the covalent nature of the metal complexes in dimethyl sulphoxide was confirmed by molar conductance values in the range $19.68-46.80 \Omega^{-1} \mathrm{~cm}^{2}$ $\mathrm{mol}^{-1[19]}$.

Table 1: Analytical data of Aspirin, Riboflavin and their metal(II) complexes.

\begin{tabular}{|c|c|c|c|c|c|c|c|}
\hline Complexes & Formula Mass & Color & D.T $\left({ }^{\circ} \mathrm{C}\right)$ & $\%$ Yield & $\% \mathbf{M}(\operatorname{Exp})$ & ${ }^{\Lambda} \mathbf{m}$ & $\mu_{\text {eff }}($ B.M) \\
\hline HL & 180.16 & White & $* 136$ & - & - & - & - \\
\hline $\mathbf{H L}^{2}$ & 376.36 & yellow & 280 & - & - & - & - \\
\hline$\left[\left\{\mathrm{Mn}(\mathrm{HL})\left(\mathrm{HL}^{2}\right)\right\}_{2} \mathrm{Cl}_{2}\right] \cdot 4 \mathrm{H}_{2} \mathrm{O}$ & 1365.94 & Yellow & 270 & 50 & $8.05(7.46)$ & 19.68 & 1.42 \\
\hline$\left[\mathrm{Fe}(\mathrm{HL})\left(\mathrm{HL}^{2}\right) \mathrm{SO}_{4}\right] \cdot \mathrm{H}_{2} \mathrm{O}$ & 726.31 & Brown & 275 & 60 & $7.67(7.67)$ & 26.80 & 3.92 \\
\hline$\left[\mathrm{Co}(\mathrm{HL})\left(\mathrm{HL}^{2}\right) \mathrm{Cl}_{2}\right] \cdot 1 / 2 \mathrm{H}_{2} \mathrm{O}$ & 638.38 & Yellow & 265 & 70 & $8.62(8.67)$ & 46.80 & 4.63 \\
\hline$\left[\mathrm{Ni}(\mathrm{HL})\left(\mathrm{HL}^{2}\right) \mathrm{Cl}_{2}\right] \cdot \mathrm{H}_{2} \mathrm{O}$ & 722.22 & yellow & 272 & 60 & $8.08(8.13)$ & 22.70 & 2.06 \\
\hline$\left[\left\{\mathrm{Cu}(\mathrm{HL})\left(\mathrm{HL}^{2}\right)\right\}_{2} \mathrm{Cl}_{2}\right]$ & 1311.94 & yellow & 290 & 60 & $9.76(9.20)$ & 19.76 & 1.45 \\
\hline$\left[\mathrm{Zn}(\mathrm{HL})\left(\mathrm{HL}^{2}\right) \mathrm{SO}_{4}\right]$ & 717.89 & Yellow & 277 & 70 & $9.10(9.12)$ & 31.10 & 0.54 \\
\hline
\end{tabular}

Keywords: D.T- Decomposition temperature; ${ }^{*}$ Melting point; M- Metal, Exp-Experimental, HL- Aspirin, $\mathrm{HL}^{2}-\operatorname{Riboflavin} \Lambda_{\mathrm{M}}=\Omega^{-1} \mathrm{~cm}^{2} \mathrm{~mol}{ }^{-1}$.

\section{Electronic spectra and magnetic moment measurements}

The solid reflectance spectra of the drugs showed two bands at $33.00 \mathrm{kK}$ and $41.49 \mathrm{kK}-51.02 \mathrm{kK}$ due to $\pi \rightarrow \pi^{*}$ and charge transfer(CT) respectively ${ }^{[11]}$. The spectrum of the $\mathrm{Mn}$ (II) complex indicated ${ }^{2} \mathrm{~T}_{2 \mathrm{~g}} \rightarrow{ }^{2} \mathrm{~A}_{1 \mathrm{~g}}$ and ${ }^{2} \mathrm{~T}_{2 \mathrm{~g}} \rightarrow{ }^{2} \mathrm{~B}_{1 \mathrm{~g}}$ transitions at $12.73 \mathrm{kK}$ and $22.22 \mathrm{kK}$ respectively, typical of low spin octahedral geometry. This complex had a moment of 1.42 B.M which was lower than the reported value of $1.73-2.2$ B.M for low spin octahedral Mn(II) complexes due to antiferromagnetism, operating through a Mn-Mn bond in a dimeric structure [Figure 1].

The Fe(II) complex exhibited transitions of both high spin $\left({ }^{5} \mathrm{~T}_{2 \mathrm{~g}} \rightarrow{ }^{5} \mathrm{E}_{\mathrm{g}}\right)$ and low spin $\left({ }^{1} \mathrm{~A}_{1 \mathrm{~g}} \rightarrow{ }^{1} \mathrm{~T}_{1 \mathrm{~g}}\right)$ octahedral geometry at $12.12 \mathrm{kK}$ and $20.83 \mathrm{kK}$ respectively. A moment of $5.0-5.6$
B.M is usually expected for high spin Fe(II) complexes while low spin octahedral Fe(II) complexes are expected to be diamagnetic. In this study, an observed moment of 3.92 B.M was complementary of equilibrium between high spin and low spin octahedral forms $^{[20]}$.

Similarly, the $\mathrm{Ni}(\mathrm{II})$ complex exhibited transitions ${ }^{3} \mathrm{~A}_{2 \mathrm{~g}}$ $\rightarrow{ }^{3} \mathrm{~T}_{2 \mathrm{~g}}$ and ${ }^{1} \mathrm{~A}_{1 \mathrm{~g}} \rightarrow{ }^{1} \mathrm{~B}_{1 \mathrm{~g}}$ typical of spin crossover at $12.77 \mathrm{kK}$ and $18.62 \mathrm{kK}$ respectively. Room temperature magnetic moments in the range 2.8 - 3.3 B.M have been reported for high spin octahedral Ni(II) complexes, while low spin octahedral Ni(II) complexes had moments in the range 0.78 - 1.68 B.M. However, an observed moment of 2.06 B.M for this complex corroborated spin cross over, i.e. equilibrium between the high spin octahedral 
and low spin octahedral geometry[ ${ }^{[21]}$.

The Co(II) complex had three absorption bands at $14.60 \mathrm{kK}, 16.95 \mathrm{kK}$ and $21.28 \mathrm{kK}$ assigned to ${ }^{4} \mathrm{~T}_{1 \mathrm{~g}}(\mathrm{~F}) \rightarrow{ }^{4} \mathrm{~T}_{2 \mathrm{~g}}$, ${ }^{4} \mathrm{~T}_{1 \mathrm{~g}}(\mathrm{~F}) \rightarrow{ }^{4} \mathrm{~A}_{2 \mathrm{~g}}$ and ${ }^{4} \mathrm{~T}_{1 \mathrm{~g}}(\mathrm{~F}) \rightarrow{ }^{4} \mathrm{~T}_{1 \mathrm{~g}}(\mathrm{P})$ transitions, typical of a high spin octahedral geometry. This geometry was corroborated by a room temperature magnetic moment of 4.63 B.M $\mathrm{M}^{[8]}$.

The $\mathrm{Cu}$ (II) complex had transitions, ${ }^{2} \mathrm{~B}_{1 \mathrm{~g}} \rightarrow{ }^{2} \mathrm{~B}_{2 \mathrm{~g}}$ and ${ }^{2} \mathrm{~B}_{1 \mathrm{~g}}$ $\rightarrow{ }^{2} \mathrm{E}_{\mathrm{g}}$, typical of a distorted octahedral geometry at $13.70 \mathrm{kK}$ and $20.37 \mathrm{kK}$ respectively. This complex had a moment of 1.45 B.M suggestive of anti ferromagnetism ${ }^{[22]}$, operating through a $\mathrm{Cu}-\mathrm{Cu}$ structure, such that each copper atom had a moment of about 0.73 B. M [Figure 1]. The Zn(II) complex had only metal $\rightarrow$ ligand $\mathrm{CT} \sim 50.0 \mathrm{kK}$ and it was expectedly diamagnetic with a moment of 0.54 B.M ${ }^{[11]}$. Thus, the drugs, Aspirin and Riboflavin, were suitable for the formation of both high spin and low spin metal(II) complexes with unique magnetic properties of anti-ferromagnetisms and spin-cross over. In the absence of variable temperature magnetic moment measurements and suitable crystals for x-ray diffraction measurements, the assigned geometries were however tentative.

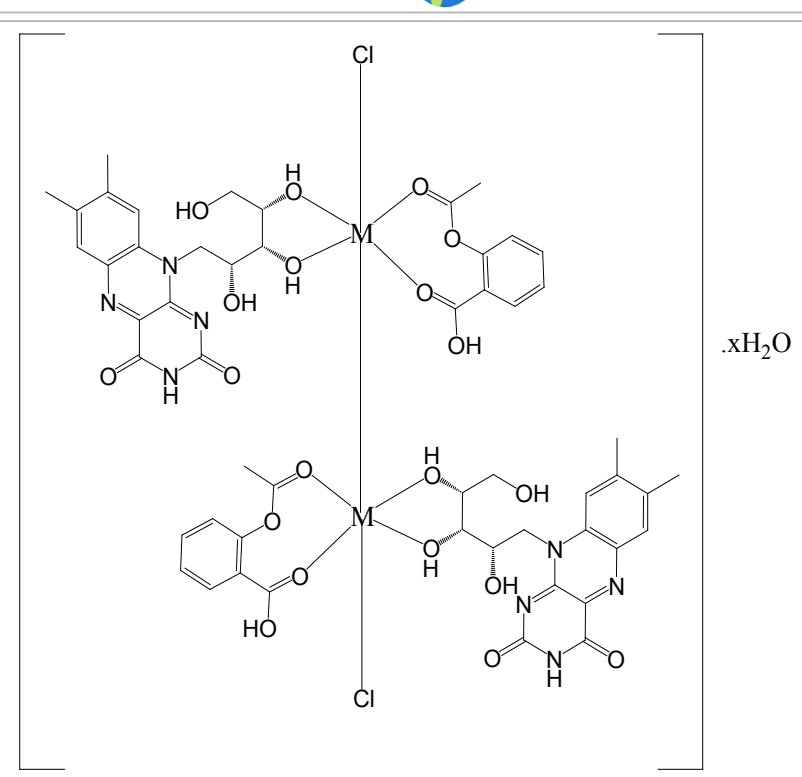

Figure 1: Proposed structure for the $\mathrm{Mn}(\mathrm{II})\{\mathrm{x}=4\}$ and $\mathrm{Cu}(\mathrm{II})\{\mathrm{x}=0\}$ complexes.

\section{Infrared spectroscopy}

The IR spectra of the drugs and their metal complexes are recorded in Table 2. The IR spectra of Aspirin and Riboflavin showed bands at $3457 \mathrm{~cm}^{-1}$ and $3441 \mathrm{~cm}^{-1}$ respectively assigned to $v(\mathrm{O}-\mathrm{H})$ stretching vibration ${ }^{[9,12]}$. This band in Aspirin was the same in the metal complexes, corroborating non coordination of the hydroxy oxygen in aspirin. Meanwhile, this band shifted in Riboflavin due to the coordination of the hydroxy oxygen atom ${ }^{[12]}$. The strong bands at $1754 \mathrm{~cm}^{-1}, 1683 \mathrm{~cm}^{-1}, 1606 \mathrm{~cm}^{-1}, 1732 \mathrm{~cm}^{-1}$, $1648 \mathrm{~cm}^{-1}$ and $1622 \mathrm{~cm}^{-1}$, in Aspirin (HL) and Riboflavin $\left(\mathrm{HL}^{2}\right)$ respectively were assigned as $v(\mathrm{C}=\mathrm{O})$. The former three bands shifted to the range $1732-1621 \mathrm{~cm}^{-1}$, corroborating coordination of the carbonyl oxygen atoms of the Aspirin in the metal complexes. However, the latter three bands remained un-shifted in Riboflavin due to non coordination of the carbonyl oxygen atom of Ribofla$\operatorname{vin}^{[14]}$.

Table 2: Infrared $\left(\mathrm{cm}^{-1}\right)$ and Electronic spectral data of Aspirin, Vitamin $\mathrm{B}_{2}$ and their mixed metal.

\begin{tabular}{|l|l|l|l|l|l|}
\hline Compound & $\boldsymbol{v N}-\mathbf{H} / \boldsymbol{v O}-\mathbf{H}$ & $\boldsymbol{v} \mathbf{C}=\mathbf{O}$ & $\boldsymbol{v} \mathbf{C}=\mathbf{N}$ & $\boldsymbol{v} \mathbf{M}-\mathbf{O}$ & Absorption Band (kK) \\
\hline $\mathbf{H L}$ & 3457 & 175416831606 & - & - & 51.0241 .4933 .00 \\
\hline $\mathbf{H L}^{2}$ & 34413377 & 173216481622 & 158115481504 & 572533518 & 51.0246 .5144 .05 \\
\hline$\left[\left\{\mathbf{M n}(\mathbf{H L})\left(\mathbf{H L}^{2}\right)\right\}_{2} \mathbf{C l}_{2}\right] \cdot \mathbf{4 H} \mathbf{O}$ & 34963376 & 173316491621 & 158115461505 & 595502486474 & 22.2212 .73 \\
\hline$\left[\mathbf{F e}(\mathbf{H L})\left(\mathbf{H L}^{2}\right) \mathbf{S O}_{\mathbf{4}}\right]$ & 3438 & 173216471622 & 158015471504 & 572533518501 & 26.4620 .8312 .12 \\
\hline$\left[\mathbf{C o}(\mathbf{H L})\left(\mathbf{H L}^{2}\right) \mathbf{C l}_{2}\right] \cdot \mathbf{H}_{\mathbf{2}} \mathbf{O}$ & 3421 & 17321647 & 158115451505 & 571518502472 & 21.2816 .9514 .60 \\
\hline$\left[\mathbf{N i}(\mathbf{H L})\left(\mathbf{H L}^{2}\right) \mathbf{C l}_{2}\right] \cdot \mathbf{H}_{2} \mathbf{O}$ & 3496,3388 & 173216481621 & 158015461504 & 595519501486 & 18.6212 .77 \\
\hline$\left[\left\{\mathbf{C u}(\mathbf{H L})\left(\mathbf{H L}^{2}\right)\right\}_{2} \mathbf{C l}_{2}\right]$ & 3440 & 173216481622 & 158015461504 & 595533518501 & 48.3120 .3713 .70 \\
\hline$\left[\mathbf{Z n}(\mathbf{H L})\left(\mathbf{H L}^{2}\right) \mathbf{S O}_{\mathbf{4}}\right]$ & 3453 & 17321647 & 158015471502 & 571422 & 50.7646 .51 \\
\hline
\end{tabular}

HL-Aspirin; $\mathrm{HL}^{2}$ - Vitamin $\mathrm{B}_{2}$

Furthermore, the bands at $1581 \mathrm{~cm}^{-1}, 1548 \mathrm{~cm}^{-1}$ and $1504 \mathrm{~cm}^{-1}$ were assigned to $v(\mathrm{C}=\mathrm{N})$ in Riboflavin. These bands remained unshifted in the metal complexes thus confirming non coordination through its imine nitrogen atom ${ }^{[9]}$. The new bands in the range $422-595 \mathrm{~cm}^{-1}$ were assigned to $v(\mathrm{M}-\mathrm{O})$ due to the coordination of the hydroxy oxygen atoms of the Riboflavin, oxygen atoms of the carbonyl in Aspirin and sulphate to metal ions ${ }^{[9,14]}$. On the contrary, these bands were absent in the spectra of the Riboflavin and Aspirin thus confirming coordination in the metal complexes.

\section{Antibacterial activities}

The antibacterial activities of the drugs and its metal complexes against Bacillus sp., Pseudomonas sp., Klebsiella sp., Enterobacteria sp., S. aureus, S. epidermidis and E. coli are presented in Table 3. Riboflavin, Aspirin and all the metal(II) complexes showed no activity against all the bacteria used. Exceptions were $\left[\mathrm{Co}(\mathrm{HL})\left(\mathrm{HL}^{2}\right) \mathrm{Cl}_{2}\right] \cdot \mathrm{H}_{2} \mathrm{O},\left[\mathrm{Ni}(\mathrm{HL})\left(\mathrm{HL}^{2}\right) \mathrm{Cl}_{2}\right] \cdot \mathrm{H}_{2} \mathrm{O}$ and $\left[\mathrm{Cu}(\mathrm{HL})\left(\mathrm{HL}^{2}\right) \mathrm{Cl}_{2}\right] \cdot \mathrm{H}_{2} \mathrm{O}$ which showed activities of 12.0 $\mathrm{mm}, 9.0 \mathrm{~mm}, 6.0 \mathrm{~mm}$ and $11.0 \mathrm{~mm}$ against Klebsiella sp., $B a-$ cillus sp., S. epidermidis and $S$. aureus respectively. Generally, metal(II) complexes are expected to be more effective than the metal-free ligand, due to chelation, which reduces the polarity of the metal atom and increases its lipophilic character, thus favoring its permeation through the lipid layers of the bacterial membrane. Hence, the general inactivity of these metal complexes may be attributed to their probable lipophobic nature ${ }^{[12]}$, and the fact that Aspirin and Riboflavin are bacteriostatic and growth supplements respectively ${ }^{[6,7]}$. 
Complexes of Mixed Drugs Aspirin and Vitamin $\mathrm{B}_{2}$

Table 3: Antibacterial activities of Aspirin, Riboflavin and their metal(II) complexes.

\begin{tabular}{|c|c|c|c|c|c|c|c|}
\hline Bacteria Complex & S. aureus & Enterobacteria sp & Pseudomonas sp & S. epidermidis & Klebsiella sp & Bacillus sp & E. coli \\
\hline Streptomycin & 30 & 20 & 25 & 20 & 32 & 25 & 13 \\
\hline HL & $\mathrm{R}$ & $\mathrm{R}$ & $\mathrm{R}$ & $\mathrm{R}$ & $\mathrm{R}$ & $\mathrm{R}$ & $\mathrm{R}$ \\
\hline $\mathbf{H L}^{2}$ & $\mathrm{R}$ & $\mathrm{R}$ & $\mathrm{R}$ & $\mathrm{R}$ & $\mathrm{R}$ & $\mathrm{R}$ & $\mathrm{R}$ \\
\hline$\left[\left\{\mathrm{Mn}(\mathrm{HL})\left(\mathrm{HL}^{2}\right)\right\}_{2} \mathrm{Cl}_{2}\right] \cdot 4 \mathrm{H}_{2} \mathrm{O}$ & $\mathrm{R}$ & $\mathrm{R}$ & $\mathrm{R}$ & $\mathrm{R}$ & $\mathrm{R}$ & $\mathrm{R}$ & $\mathrm{R}$ \\
\hline$\left[\mathrm{Fe}(\mathrm{HL})\left(\mathrm{HL}^{2}\right) \mathrm{SO}_{4}\right]$ & $\mathrm{R}$ & $\mathrm{R}$ & $\mathrm{R}$ & $\mathrm{R}$ & $\mathrm{R}$ & $\mathrm{R}$ & $\mathrm{R}$ \\
\hline$\left[\mathrm{Co}(\mathrm{HL})\left(\mathrm{HL}^{2}\right) \mathrm{Cl}_{2}\right] .2 \mathrm{H}_{2} \mathrm{O}$ & $\mathrm{R}$ & $\mathrm{R}$ & $\mathrm{R}$ & 12 & 9 & $\mathrm{R}$ & $\mathrm{R}$ \\
\hline$\left[\mathrm{Ni}(\mathrm{HL})\left(\mathrm{HL}^{2}\right) \mathrm{Cl}_{2}\right] \cdot \mathrm{H}_{2} \mathrm{O}$ & 6 & $\mathrm{R}$ & $\mathrm{R}$ & $\mathrm{R}$ & $\mathrm{R}$ & $\mathrm{R}$ & $\mathrm{R}$ \\
\hline$\left[\left\{\mathrm{Cu}(\mathrm{HL})\left(\mathrm{HL}^{2}\right)\right\}_{2} \mathrm{Cl}_{2}\right] \cdot \mathrm{H}_{2} \mathrm{O}$ & $\mathrm{R}$ & $\mathrm{R}$ & $\mathrm{R}$ & $\mathrm{R}$ & $\mathrm{R}$ & 11 & $\mathrm{R}$ \\
\hline$\left[\mathrm{Zn}(\mathrm{HL})\left(\mathrm{HL}^{2}\right) \mathrm{SO}_{4}\right]$ & $\mathrm{R}$ & $\mathrm{R}$ & $\mathrm{R}$ & $\mathrm{R}$ & $\mathrm{R}$ & $\mathrm{R}$ & $\mathrm{R}$ \\
\hline
\end{tabular}

HL- Aspirin; $\mathrm{HL}^{2}$-Riboflavin; R-Resistance

\section{Conclusion}

Some $\mathrm{Mn}(\mathrm{II}), \mathrm{Fe}(\mathrm{II}), \mathrm{Co}(\mathrm{II}), \mathrm{Ni}(\mathrm{II}), \mathrm{Cu}(\mathrm{II})$ and $\mathrm{Zn}(\mathrm{II})$ complexes of the mixed drugs, Aspirin and Riboflavin (Vitamin $\mathrm{B}_{2}$ ) were synthesized and characterized. Room temperature magnetic moment measurements indicated that the $\mathrm{Mn}(\mathrm{II})$ and $\mathrm{Cu}(\mathrm{II})$ complexes were antiferromagnetic, while $\mathrm{Fe}(\mathrm{II})$ and $\mathrm{Ni}(\mathrm{II})$ complexes exhibited spin crossover. In addition the metal complexes assumed a probable 6-coordinate octahedral geometry and were non-electrolytes in DMSO. The in-vitro antibacterial activities studies showed that most of the metal(II) complexes and the drugs had no activity against Bacillus sp, E. coli, Pseudomonas sp, Klebsiella sp, Staphylococcus spp and Enterobacteria sp.

Acknowledgement: The University of Ibadan, Ibadan, Nigeria is hereby acknowledged for the provision of the research chemicals and equipments.

Conflict of interests: The authors have declared that no competing interests exist.

\section{References}

1. Lippard, S. Chapter 1-metal ion chemistry for sustaining life in medicinal inorganic chemistry. ACS Symposium Series. (2005) American Chemical Society Washington DC.

2. Obaleye, J.A., Bamigboye, M.O., Abdulmolib, S. Synthesis, characterization and antimicrobial activity of some mixed sulfamethoxazole-cloxacillin metal drug complexes. (2012) Int J Chem 22(2): 105108.

3. Chan, A.T., Arber, N., Burn, J., et al. Aspirin in the chemo prevention of colorectal neoplasia: an overview. (2012) Cancer Prev Res (Phila) 5(2): 164-178.

4. Cuzick, J., Thorat, M.A., Bosetti, C., et al. Estimates of benefits and harms of prophylactic use of aspirin in the general population. (2014) Ann Oncol 26(1): 47-57.

5. Schoenen, J., Jacquy, J., Lenaerts, M. Effectiveness of high-dose riboflavin in migraine prophylaxis. A randomized controlled trial. (1998) Neurology 50(2): 466-470.

6. Powers, H.J. Riboflavin (vitamin B-2) and health. (2003) Am J Clin Nutr 77(6): 1352-1360.

7. Obaleye, J.A., Orjiekwe, C.L., Famurewa, O. Effects of some novel Ascorbic acid metal complexes on selected bacterial and fungal Species. (1994) J Sci IR 5(4): 154-157.

8. Al-Saif, F.A., Refat, M.S. Ten metal complexes of vitamin B3/niacin:
Spectroscopic, thermal, antibacterial, antifungal, cytotoxicity and antitumor studies of $\mathrm{Mn}(\mathrm{II}), \mathrm{Fe}(\mathrm{III}), \mathrm{Co}(\mathrm{II}), \mathrm{Ni}(\mathrm{II}), \mathrm{Cu}(\mathrm{II}), \mathrm{Zn}(\mathrm{II}), \mathrm{Pd}(\mathrm{II})$, $\mathrm{Cd}(\mathrm{II}), \mathrm{Pt}(\mathrm{IV})$ and $\mathrm{Au}(\mathrm{III})$ complexes.( 2015) J Molecular Structure 1021: 40-52.

9. Spence, J.T., Peterson, E.R. Infra-red spectra of metal complexes of Riboflavin. (1962) J Inorg Nuclear Chem 24(6): 601-608.

10. Lawal, A., Obaleye, J.A. Synthesis, characterization and antibacterial activity of aspirin and paracetamol-metal complexes. (2007) Biokemistri 19: 9-15.

11. Rao, R., Singh, R. Synthesis, characterization of divalent manganese, cobalt, nickel, copper, and zinc complexes with nicotinic acid. (1981) J Molecular Structure 71: 23-30.

12. Harminder, K., Kanav, D., Jaspreet, K., et al. Synthesis and evaluation of diorganotin(IV) and triorganotin(IV) derivatives of Aspirin, Paracetamol and Metronidazole as antimicrobial agents. (2013) American Journal of Drugs and Development 3(1): 13-22.

13. Osowole, A.A., Agbaje O.B.A., Ojo, B.O. Synthesis, characterization and antibacterial properties of some heteroleptic metal(II) complexes of Paracetamol and Vanillin. (2014) Asian J Pharm Clin Res 7(3): 145-149.

14. Osowole, A.A., Wakil, S.M., Malumi, E.O. Synthesis, characterization, antioxidant and antimicrobial activities of some metal(II) complexes of the mixed-ligand, Vitamin B2 and Benzoic acid. (2015) Elixir Appli Chem 79: 30370- 30374.

15. Osowole, A.A., Agbaje, O.B.A., Wakil, S.M. Synthesis, characterization and biological activity of some mixed metal(II) complexes of Paracetamol and Benzoic acid. (2015) International Journal of Applied Medical Sciences 1: 77-87.

16. Osowole, A.A., Malumi, E.O., Wakil, S.M., et al. Synthesis, characterization, antioxidant and antimicrobial activities of some mixed-drug metal(II) complexes of vitamins B2 and B3. (2015) International Journal of Applied Medical Sciences 1: 88-97.

17. Vitorino, H.A., Mantovanelli, L., Zanotto, F.P., et al. Iron Metallodrugs: Stability, redox activity and toxicity against Artemia salina. (2015) Plos one 10(4): e0121997.

18. Guo, J., Sadler, P. J. Medicinal Inorganic Chemistry. (1999) Advances in Inorganic Chemistry 49: 183-306.

19. Geary, W. J. The use of conductivity measurements in organic solvents for the characterization of coordination compounds. (1971) Coord Chem Rev 7(1): 81-122.

20. Olguín, J., Brooker, S. Spin crossover active iron(II) complexes of selected pyrazole-pyridine/pyrazine ligands.( 2011) Coordination Chemistry Reviews 255(1-2): 203-240.

21. Goodwin, H. A. Spin crossover in Cobalt(II) Systems. (2004) Top Curr Chem 234: 23-27.

22. Kang, L.C., Chen, X., Wang, X.S., et al. Hydrogen cyanamido bridged multinuclear copper(II) complexes: from strong antiferromagnetic couplings to weak ferromagnetic couplings. (2011) Dalton Trans 40(19): 5200-5209. 